\title{
The new CAP must be linked more closely to the UN Sustainable Development Goals
}

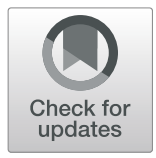

Alan Matthews

Correspondence: alan.matthews@ tcdie

Professor Emeritus of European Agricultural Policy at Trinity College, Dublin, Ireland
Sustainable agricultural production, including its economic, environmental and social dimensions, is now explicitly recognised as one of the principal objectives for the EU's Common Agricultural Policy (CAP). This is in line with the 2030 Agenda for Sustainable Development adopted in September 2015 by the 193 Member States of the United Nations, which includes 17 Sustainable Development Goals (SDGs) with 169 targets and 230 indicators.

The SDGs succeeded the Millennium Development Goals, a set of eight goals agreed in 2000 ranging from halving extreme poverty and hunger to promoting gender equality and reducing child mortality, by the target date of 2015. Both agendas are based on goals intended to be clear, time-bound and measurable. However, while the MDGs were established in the context of 'rich donors helping poor recipients', the SDGs are universal goals relevant to every country.

Yet despite a formal recognition that the CAP should contribute to achieving the SDGs, the Commission's legal proposal for the CAP post 2020 fails to properly align with the 17 goals. In particular, it fails to provide a measurable framework to enable the contribution of the CAP to the SDGs to be assessed. The proposed CAP legislation should be amended to rectify this omission.

The EU played an active role in shaping the 2030 Agenda and quickly committed to implementing its goals in both its external and internal policies. However, concrete initiatives were slow in coming. In December 2019, the European Council was still urging the Commission 'to elaborate without further delay a comprehensive implementation strategy outlining timelines, objectives and concrete measures to reflect the 2030 Agenda and mainstream the SDGs in all relevant EU internal and external policies, based on what more needs to be done by 2030, in terms of EU policy, legislation, governance structures for horizontal coherence and means of implementation'.

Each year, Eurostat publishes a monitoring report on EU progress towards implementing the SDGs, based on around 100 indicators selected both for their policy relevance from an EU perspective as well as data availability. However, as the European Court of Auditors observed in a critical report, these monitoring data are not a substitute for a regular Commission assessment of the contribution of the EU budget or EU policies to the SDGs (ECA 2019).

(c) The Author(s). 2020 Open Access This article is licensed under a Creative Commons Attribution 4.0 International License, which permits use, sharing, adaptation, distribution and reproduction in any medium or format, as long as you give appropriate credit to the original author(s) and the source, provide a link to the Creative Commons licence, and indicate if changes were made. The images or other third party material in this article are included in the article's Creative Commons licence, unless indicated otherwise in a credit line to the material. If material is not included in the article's Creative Commons licence and your intended use is not permitted by statutory regulation or exceeds the permitted use, you will need to obtain permission directly from the copyright holder. To view a copy of this licence, visit http://creativecommons.org/licenses/by/4.0/. 
This criticism has particular force when applied to the CAP, given that sustainable food and agricultural production has potential relevance for a majority of the SDGs. In its 2017 Communication The Future of Food and Farming in which it set out its ideas for the CAP framework post 2020, the Commission identified 13 of the 17 SDGs to which the CAP could make a contribution while noting that the CAP objectives should fulfil both Treaty obligations as well as a number of SDGs.

The Commission has emphasised in its legal proposal for the CAP in June 2018 that its regulations would move the CAP towards greater alignment with the SDGs. It presumably had in mind its proposals to increase the climate and environmental ambition of the CAP. However, the only reference to the SDGs in the legislation comes in the preamble where the need to implement the Paris Agreement and the SDGs is used to motivate mainstreaming climate action in the EU budget and specifically that actions under the CAP are expected to contribute $40 \%$ of the overall CAP budget to climate objectives. The failure to make an explicit link between the CAP objectives and the SDGs in the legislation itself misses an opportunity to give greater direction to Member States on the factors they should consider when drawing up their national CAP Strategic Plans.

One recent study that scrutinized the performance of the CAP with respect to the SDGs concluded that it could make a substantial contribution to nine SDGs, yet its current instruments provide some support only to SDGs 2 (zero hunger) and 1 (no poverty) and limited to no support to all other SDGs (Pe'er et al. 2019). This assessment was based on expert opinion, including a review of relevant academic literature. The authors concluded that 'To address societal demands for sustainability, the CAP post-2020 needs a more coherent set of clear objectives, linked to SDGs and associated with measurable targets' (p. 450).

While the more explicit definition of nine specific objectives for the CAP post 2020 certainly better reflects some (but not all) of the SDGs, the lack of measurable, timebound targets linked to the SDGs is a crucial weakness in the legislation. The CAP has a comprehensive monitoring and evaluation framework based on indicators at different policy stages. Its Common Monitoring and Evaluation Framework (CMEF), introduced with the aim of measuring the performance of the CAP reform 2014-2020, counts 45 context indicators, 84 output indicators, 41 result indicators, 24 target indicators and 16 impact indicators.

Scown and Nicholas (2020) make a semantic mapping of these indicators (also including indicators from the Agri-Environmental Indicators maintained by Eurostat) with the target indicators for the SDGs (using the 100 SDG target indicators selected by Eurostat as policy relevant for the EU). They identify 29 CAP indicators that map to the SDG indicators. They concluded that there are several relevant SDGs for which there are no CAP indicators. They also noted that, while target indicators were generally well aligned with SDG indicators, the CAP does not specify values for these indicators that should be met by a certain time. In the legal proposal for the CAP post 2020, it is proposed to reduce the number of indicators (excluding context indicators) from 146 to 101 in an effort at simplification. But there is no explicit attempt to link the indicator set to relevant SDGs.

Suggestions have been made as to how to better align CAP indicators with the SDGs. Schwoob, Hege and Aubert (2018) determined which SDGs might be relevant for the 
CAP by examining the 169 targets associated with the 17 SDGs and asking which of these could be relevant to a sectoral policy such as agricultural policy. By taking a broad view of agriculture and its relationships to territories, food systems and the bioeconomy, they identified 47 targets covering all SDGs (except for SDG 16 (peace, justice and strong institutions) and SDG 17 (partnerships for the goals) that they assessed as being relevant to the CAP. They proposed a list of indicators that could be used to operationalize these targets for 21 of the selected 47 targets but did not attempt to evaluate how many of these are included either in the current or proposed CMEF.

Another contribution was made in the Commission's impact assessment accompanying its CAP legislative proposal (European Commission 2018). This included an innovative Multi-Criteria Analysis that scored the various policy reform options considered in the impact assessment against a list of criteria/indicators (referred to as operational objectives) that were linked to each of the new CAP main and specific objectives. These operational objectives were given values in each scenario option based either on quantitative model outcomes or qualitative expert judgement. The impact assessment highlighted that one of the cross-cutting objectives of the new CAP is to improve sustainable development for farming, food and rural areas and that this objective is tightly intertwined with the SDGs. It thus mapped the SDGs against its proposed operational objectives of the CAP.

Altogether, 13 SDGs were covered in the impact assessment. Clear links were identified with ten of these SDGs $(1,2,3,6,8,9,10,13,15)$, meaning that the operational objectives could be directly associated with one or several SDG targets. Two SDGs were covered indirectly ( 4 and 5). In these cases, the operational objectives did not explicitly address these SDG themes but they were reflected in the Multi-Criteria Analysis. The two remaining SDGs (12 and 17) were deemed overarching goals that could be linked to the whole exercise. The impact assessment did not make the final step of identifying specific indicators to measure progress for each of the operational objectives (with two exceptions). However, it remains the most explicit attempt from the Commission side to align the CAP with the SDGs.

Since the publication of the Commission's legal proposal for the next CAP, the new Commission has published its proposal for a European Green Deal. The agricultural dimension of the European Green Deal is the Farm to Fork (F2F) Strategy which the Commission also sees as central to its agenda to achieve the SDGs. But many questions remain as to how the F2F objectives will be integrated into the CAP reform process and reflected in national CAP Strategic Plans.

At the moment, the Commission's claim that the new CAP addresses the SDGs is litthe more than a rhetorical device. Given that the EU is committed to implementing the SDGs, this needs to change. A lot of groundwork has been done to identify the SDG targets to which the CAP can contribute. What is needed now is to translate the relevant SDG targets into measurable, time-bound indicators so that progress can be evaluated, and potential incoherencies assessed. The proposed set of CMEF indicators is clearly inadequate for this purpose.

The CAP post 2020 legislation should be revised to include an explicit reference that the policy is required to contribute to achieving the SDGs and calling for an indicator set to measure progress. As the new CAP framework will be delayed for at least 1 and possibly 2 years, the Commission should initiate the necessary work without waiting 
for this legislation. Individual Member States have also signed up to the SDGs and committed to their implementation. Efforts are thus also required at the national level to link the priorities identified in the national CAP Strategic Plans with the SDGs which do not need to wait until the CAP legislation is approved.

\section{Author's contributions}

The author(s) read and approved the final manuscript.

\section{Competing interests}

The author declares that he has no competing interests.

Published online: 03 August 2020

\section{References}

ECA (2019) Reporting on sustainability: a stocktake of EU institutions and agencies. European Court of Auditors, Luxembourg. European Commission. 2018. Impact assessment accompanying the Commission's legislative package on the Common Agricultural Policy post 2020, Documents \{COM(2018) 392 Final $\}$ - \{COM(2018) 393 Final $\}$ - \{COM (2018) 394 Final. SWD(2018) 301 - Part 3/3. Brussels.

Pe'er G, Zinngrebe Y, Moreira F, Sirami C, Schindler S, Müller R, Bontzorlos V, Clough D, Bezák P, Bonn A (2019) A greener path for the EU Common Agricultural Policy. Science 365(6452):449-451.

Schwoob, M.-H., E. Hege, and P.-M. Aubert. 2018. Making the SDGs Count in the CAP reform: an analytical framework. Issue Brief No. 4. Paris: Institut du développement durable et des relations internationales.

Scown M, Nicholas K (2020) European agricultural policy requires a stronger performance framework to achieve the Sustainable Development Goals. Global Sustainability 3 https://doi.org/10.1017/sus.2020.5

\section{Publisher's Note}

Springer Nature remains neutral with regard to jurisdictional claims in published maps and institutional affiliations.

\section{Submit your manuscript to a SpringerOpen ${ }^{\circ}$ journal and benefit from:}

- Convenient online submission

$\checkmark$ Rigorous peer review

- Open access: articles freely available online

- High visibility within the field

- Retaining the copyright to your article 